\title{
Energy and Dynamic Properties of Hydraulic Systems
}

\author{
Martin VAŠINA, Lumír HRUŽíK, Adam BUREČEK
}

\begin{abstract}
The aim of the paper is to evaluate hydraulic systems in terms of energy and dynamic properties. There are flow and pressure losses that have influence on total efficiency of hydraulic systems. The systems are compared from lower effective to energy saving. There are described advantages and disadvantages of the systems in this work. Dynamic properties of the investigated energy saving Load-Sensing system were determined based on the system eigenfrequency. Dynamic behaviour of the system was performed by three different methods that were subsequently compared.
\end{abstract}

Keywords: dynamics; efficiency; eigenfrequency; energy losses; hydraulic systems

\section{INTRODUCTION}

Hydraulic systems are applied in many spheres $[1 \div 4]$, e.g. as drives of excavators, presses, cranes, hoists and loaders. These systems are mainly used for transmission of large forces at small sizes of equipment. Low wear, high service life, overload protection, possibility to accumulate energy and automatic motion belong to some advantages of hydraulic systems. On the contrary, these systems have certain disadvantages, e.g. pressure and flow losses, leakages, liquid compressibility and dependence of liquid viscosity on pressure and temperature. There are many requirements for hydraulic systems, e.g. acquisition costs, dependability, safety, service life, energy consumption, equipment dimensions, weight, range of operating parameters, emission reducing and dynamic behaviour. It is necessary to take into account these requirements in design of a concrete hydraulic system.

The development of energy saving technologies belongs to more important goals throughout all fields of research at the present time [5, 6]. The production and utilization with high energy efficiency for industrial practices are significant to the world economy [7]. There is a tendency for reducing energy consumption of working machines by minimizing energy losses. Energy demandingness of hydraulic systems is in general connected with pressure and flow losses $[8,9]$. This fact is reflected by increased operating costs and has a negative influence on manufacturing effectiveness and competitiveness of operators. Furthermore, excessive energy losses can cause a high-temperature heating of liquids. As a result, it is necessary to install a cooler in such a case. This fact leads to higher investment and operating costs of these hydraulic systems. For these reasons it is suitable to eliminate the energy losses in hydraulic systems by means of appropriate construction measures at the beginning of a design process.

Dynamics of hydraulic systems is connected with pressure and flow pulsations that arise from process machines (e.g. hydraulic pumps). Subsequently, they can be propagated through the fluid-filled piping system [10]. The pulsations have a negative influence on functionality and service life of hydraulic components, system tightness and stability, cavitation, pressure fluctuation in a system, noise and mechanical vibrations [11]. The eigenfrequency of hydraulic systems belongs to a qualitative dynamic measure of hydraulic drives. If the excitation frequency of a given hydraulic system is consistent with its eigenfrequency, high-amplitude pressure and flow pulsations are generated in the system. Therefore, it is necessary to avoid the operation of a given hydraulic system at its eigenfrequency. Pressure and flow pulsations are also generated at low excitation frequencies of hydraulic systems. For this reason, it is necessary to ensure the minimum system eigenfrequency [12] depending on the given hydraulic system. If unwanted mechanical vibrations occur in hydraulic systems, it is desirable to suppress them in a suitable manner, e.g. by means of elastic mounting of machines, active damped material structures and placement of accumulators in these systems [10, 13]

This paper is focused on examination of hydraulic systems in terms of energy savings and dynamic behaviour. Hydraulic systems are firstly compared in terms of energy savings, which are very important for system operators. The systems are compared from lower effective to energy saving on the basis of their efficiency. There are also described advantages and disadvantages of different hydraulic systems in this work. The second part of the paper deals with dynamic behaviour of the energy saving Load-Sensing (LS) system. The eigenfrequency of the investigated LS system at given operating conditions is determined by three different methods, namely by experimental measurement, mathematical simulation and by means of empirical formula. These methods are subsequently compared in the conclusion of the paper.

\section{EFFICIENCY OF HYDRAULIC SYSTEMS}

Energy consumption is an important parameter for operators of hydraulic systems. Energy balance of a hydraulic system is characterized by its efficiency.

The efficiency $\eta[4,14,15]$ of hydraulic systems is expressed by the ratio:

$\eta=\frac{P_{2}}{P_{1}}$

where $P_{1}$ is input power of hydraulic pump, and $P_{2}$ is effective power of a consumer.

The power $P$ is defined by the formula:

$P=Q \cdot p$, 
where $Q$ is flow of working liquid, and $p$ is working pressure.

There are different types of energy losses in hydraulic systems, e.g. pressure drops due to viscous friction in hydraulic lines, local pressure drops across throttle valves, flow losses through relief valves, energy losses in hydrostatic converters, liquid leakages etc. Energy losses are influenced by many factors, e.g. by liquid type, flow, working pressure, liquid density, temperature and viscosity, materials of hydraulic components and lengths of hydraulic lines. It is suitable to eliminate energy losses in hydraulic systems by appropriate measures. It is possible to eliminate energy losses by application of energy saving hydraulic systems too.

There are taken into account only energy losses across throttle, pressure and relief valves in this work. Other energy losses are neglected in this case. A perfect tightness in connections of hydraulic components is also assumed.

\section{ENERGY SAVING HYDRAULIC SYSTEMS}

Different connection methods of hydraulic systems and their energy balance are described in this chapter.

\subsection{System with Non-Regulatory Pump, Relief Valve and Throttle Valve}

The minimum efficiency is achieved in case of the hydraulic system with the non-regulatory hydraulic pump HP (i.e. with the constant flow $Q_{1}$ ), the relief valve RV (i.e. with the constant pressure $p_{1}$ ) and the throttle valve TV which is used in order to adjust the flow $Q_{2}$ and thereby speed of movement of the hydraulic motor HM [14, 16]. The schematic diagram of this hydraulic system and its energy balance for two operation conditions (i.e. the points $A$ and $A^{\prime}$ ) are shown in Fig. 1. There are flow losses through the relief valve and pressure drop across the throttle valve in this case. The loss flow $Q_{1}$ through the relief valve is given by the difference of the input flow $Q_{1}$ and the output flow $Q_{2}$. For the above-mentioned reasons the efficiency of the hydraulic system is given by the equation:

$$
\begin{aligned}
& \eta=\frac{Q_{2} \cdot p_{2}}{Q_{1} \cdot p_{1}}=\frac{Q_{2} \cdot p_{2}}{Q_{2} \cdot p_{2}+Q_{l} \cdot p_{1}+\Delta p_{v} \cdot Q_{2}}= \\
& =\frac{Q_{2} \cdot p_{2}}{Q_{2} \cdot p_{2}+\left(Q_{1}-Q_{2}\right) \cdot p_{1}+\left(p_{1}-p_{2}\right) \cdot Q_{2}} .
\end{aligned}
$$

The maximum efficiency $\eta_{\max }=0,38$ is obtained at the pressure $p_{2}=2 / 3 \cdot p_{1}$.

The flow $Q_{2}$ through the throttle valve is defined by the formula $[17 \div 20]$ :

$$
Q_{2}=A_{v} \cdot \mu \cdot \sqrt{\frac{2 \cdot \Delta p_{v}}{\rho}},
$$

where $A_{v}$ is throttle area, $\mu$ is flow coefficient, $\Delta p_{v}$ is pressure gradient across the throttle valve, and $\rho$ is liquid density.

It is evident from Eq. (4) that the flow $Q_{2}$ depends on the pressure gradient $\Delta p_{v}$, which is changed as a result of a load change of the hydraulic motor. For this reason, the flow $Q_{2}$ is also changed. It is a further disadvantage of this system. This deficiency is eliminated by means of two-way throttle valve with pressure gradient stabilization [17].
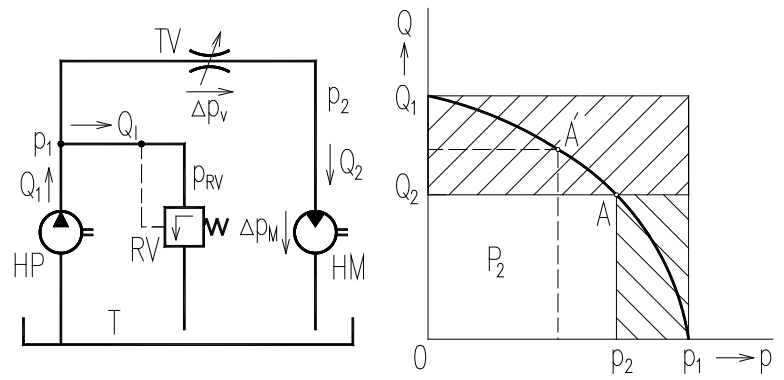

Figure 1 Schematic diagram and energy balance of hydraulic system with nonregulatory pump, relief valve and throttle valve

\subsection{System with Two-Way Throttle Valve and Pressure Gradient Stabilization}

Fig. 2 shows the hydraulic system with the two-way throttle valve and pressure gradient stabilization and its energy balance. The throttle valve TV and the pressure valve PV are arranged in series in this system. The efficiency of the system is expressed by the equation:

$$
\eta=\frac{Q_{2} \cdot p_{2}}{Q_{1} \cdot\left(p_{2}+\Delta p_{v}+\Delta p_{R}\right)},
$$

where $\Delta p_{R}$ is pressure gradient across the pressure valve.

As in the previous case, the maximum efficiency $\eta_{\max }=0,38$ is obtained at the pressure $p_{2}=2 / 3 \cdot p_{1}$. The pressure gradient $\Delta p_{v}$ across the throttle valve is maintained constant at different loads of the motor HM. For this reason the flow $Q_{2}$ according to Eq. (4) is independent on a motor load.
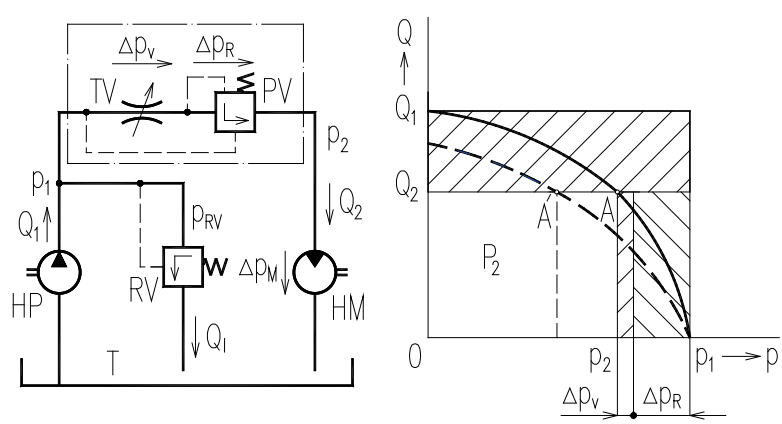

Figure 2 Schematic diagram and energy balance of hydraulic system with twoway throttle valve and pressure gradient stabilization

\subsection{System with Three-Way Throttle Valve and Pressure Gradient Stabilization}

It is possible to obtain a higher efficiency by application of the three-way throttle valve and pressure gradient stabilization [12]. In this case the throttle valve TV and the pressure valve PV are arranged in parallel (see Fig. 3 ). The relief valve RV is only used for system protection against overload. The pressure gradient across the throttle valve $\Delta p_{v}$ is constant and negligible, in this case $\Delta p_{v}=(0,5 \div 1,0) \mathrm{MPa}$. 
There are flow losses through the pressure valve and pressure drop across the throttle valve in this system. A higher efficiency of the system with the three-way throttle valve and pressure gradient stabilization is in general achieved at higher loadings of the motor HM and is given by the formula:

$$
\eta=\frac{Q_{2} \cdot p_{2}}{Q_{1} \cdot\left(p_{2}+\Delta p_{v}\right)}
$$
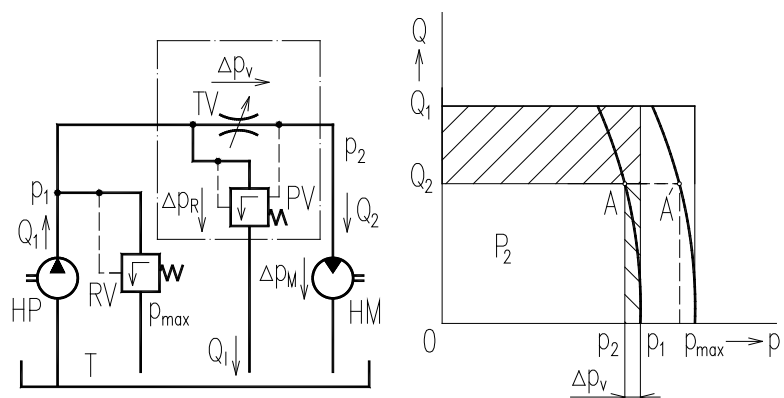

Figure 3 Schematic diagram and energy balance of hydraulic system with threeway throttle valve and pressure gradient stabilization

\subsection{System with Constant Pressure Control}

The system with the hydraulic pump HP, the pressure regulator PR and the throttle valve TV $[14,16]$ allows to achieve the maximum efficiency $\eta_{\max }=0,67$. The schematic diagram and energy balance of this system are shown in Fig. 4. There is only pressure drop across the throttle valve TV in this system. The flows are equal (i.e. $Q_{1}=Q_{2}$ ). For this reason, the efficiency of the system is expressed by the equation:

$\eta=\frac{Q_{2} \cdot p_{2}}{Q_{1} \cdot p_{1}}=\frac{p_{2}}{p_{1}}=\frac{p_{2}}{p_{2}+\Delta p_{v}}$.

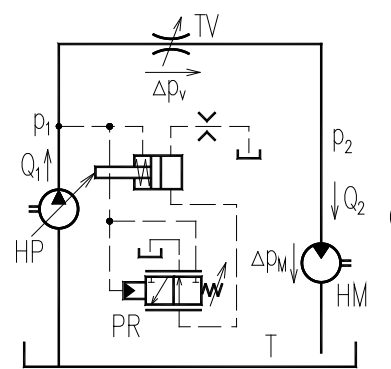

Figure 4 Schematic diagram and energy balance of hydraulic system with constant pressure control

\subsection{Load-Sensing Systems}

It is possible to obtain significant energy savings by means of Load-Sensing (LS) systems [21]. There are LS systems with open center or closed center [22]. The example of the LS system with the hydraulic pump HP and the flow regulator FR is shown in Fig. 5. The flows (i.e. $Q_{1}=Q_{2}$ ) are adjusted by the control valve $\mathrm{CV}$, most frequently by a proportional valve. For this reason, the energy dissipation into thermal energy occurs only on the control valve with the pressure gradient $\Delta p_{v}=(1 \div 2) \mathrm{MPa}$, which is maintained constant $[23,24]$ independently of a motor load. Then the flows are also independent on a load change of the motor. The efficiency of this system is given as follows [14]:

$\eta=\frac{p_{2}}{p_{1}}=\frac{p_{2}}{p_{2}+\Delta p_{v}}=\frac{1}{1+\frac{\Delta p_{v}}{p_{2}}}$.

It is evident from Eq. (8), that higher efficiencies of LS systems are in general achieved at higher operating pressures $p_{2}$.
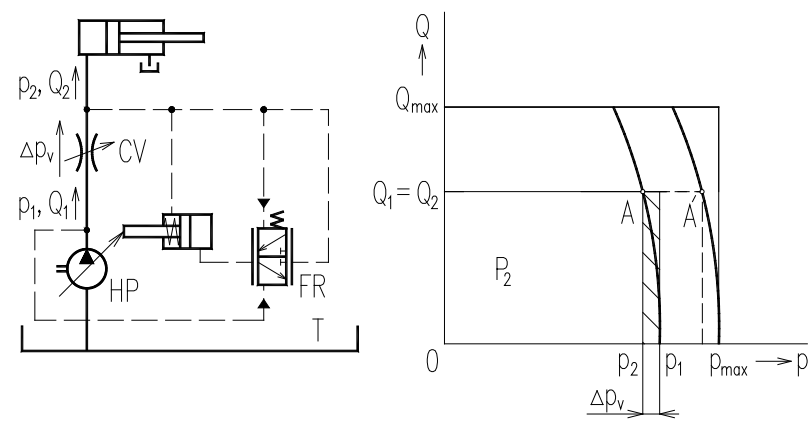

Figure 5 Schematic diagram and energy balance of Load-Sensing system

\subsection{System with Regulating Pump and Programmable Control System}

It is possible to achieve the theoretical maximum efficiency $\eta_{\max }=1$ in case of the system with the flowregulating hydraulic pump HP and a programmable control system [16] (see Fig. 6). The flow of the system is controlled on the basis of the angular displacement $\alpha$ of an axial piston hydraulic pump [25]. Real and required values of the displacement are mutually compared by means of the control system. This hydraulic system is controlled without throttle elements. It is a big advantage of the system. On the contrary, expensiveness, dynamic properties and limited application possibilities belong to disadvantages of this system.
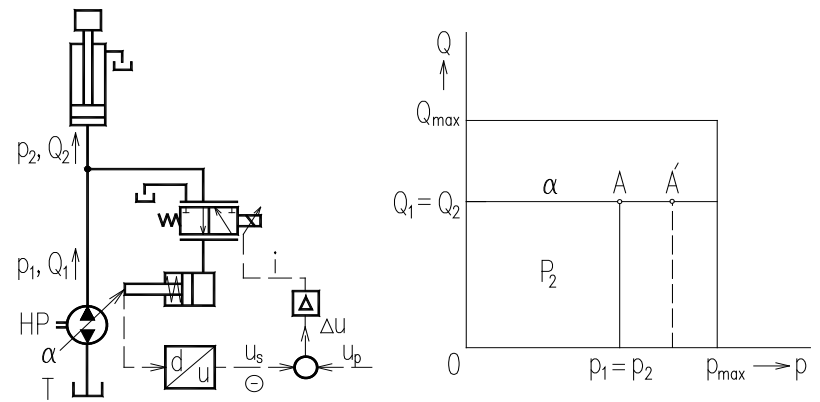

Figure 6 Schematic diagram and energy balance of hydraulic system with flowregulating pump and programmable control system

\section{DYNAMIC BEHAVIOUR OF LOAD-SENSING SYSTEM}

Dynamics of hydraulic systems belong also to important criteria at their operation. Dynamic behaviour is influenced by periodic pressure pulsations. For this reason, hydraulic components are permanently stressed. There are forced and free periodic oscillations in hydraulic systems [17]. Forced oscillations are obtained by a response to a periodic excitation signal. Free oscillations are caused by 
transient changes of systems. If the system eigenfrequency is equal to the system excitation frequency, periodic oscillations with uncontrollable pressure or flow amplitudes can be generated in the system. A system failure may also occur. For the above-mentioned reasons it is necessary to eliminate pressure and flow pulsations in hydraulic systems.

The eigenfrequency $f_{0}$ of hydraulic systems is a very important quantity in terms of dynamic assessment of the systems. It is a qualitative measure of drives. Processes of acceleration and deceleration in hydraulic systems are slow at low eigenfrequency values. Movements of hydraulic motors are uneven in this case [12]. For these reasons, it is necessary to ensure a minimum eigenfrequency value of a given hydraulic system.

The system eigenfrequency can be investigated by means of experimental measurements, mathematical simulations or empirical formulas [17].

\subsection{Investigated Load-Sensing System}

Dynamic properties were investigated on the energy saving open center Load-Sensing system, which is schematically shown in Fig. 7. The view of the system is shown in Fig. 8.

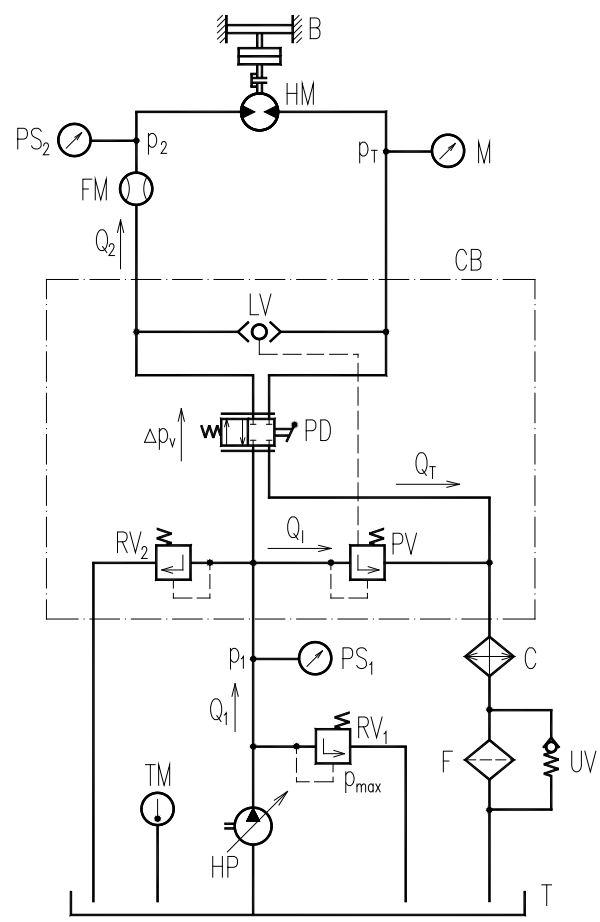

Figure 7 Schematic diagram of the investigated LS system

The hydraulic pump HP is a pressure source of the system. The relief valve $\mathrm{RV}_{1}$ is used for protection of the LS system against overload. Hydraulic oil flows through the control block CB to the hydraulic motor HM and back to the tank T (see Fig. 7). The control block consists of the proportional distributor PD, the three-way pressure valve $\mathrm{PV}$, the logical valve $\mathrm{LV}$ and the relief valve $\mathrm{RV}_{2}$. The pressure drop across the distributor remains constant independently of load change [23, 24], i.e. $\Delta p_{v}=(1 \div 2) \mathrm{MPa}$. For this reason, the output flow $Q_{2}$ is constant too. The loading device of the motor consists of the brake B (from Škoda Felicia car) and two movable disks (see Fig. 8). The disks allow to adjust a size of mass moment of inertia on the motor HM. Oil flows in the output line through the cooler $\mathrm{C}$, the filter $\mathrm{F}$ (or the unidirectional valve UV) to the tank $\mathrm{T}$. The pressures $p_{1}$ and $p_{2}$ were measured by the pressure sensors $\mathrm{PS}_{1}$ and $\mathrm{PS}_{2}$. The flow $Q_{2}$ through the motor was measured by the flowmeter FM. The above-mentioned quantities were evaluated by means of the measuring equipment M5000 Hydrotechnik (see Fig. 9). The pressure $p_{\mathrm{T}}$ was measured by the manometer $\mathrm{M}$. The thermometer TM was used for oil temperature measurement.

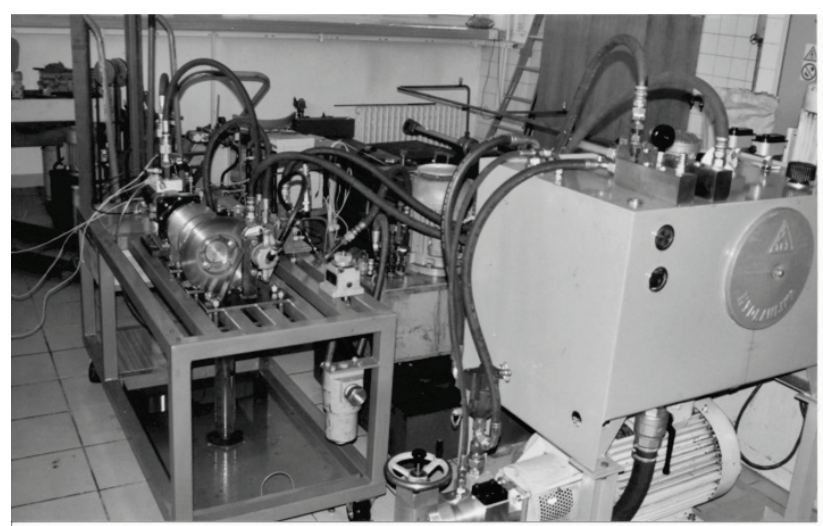

Figure 8 View of the investigated LS system

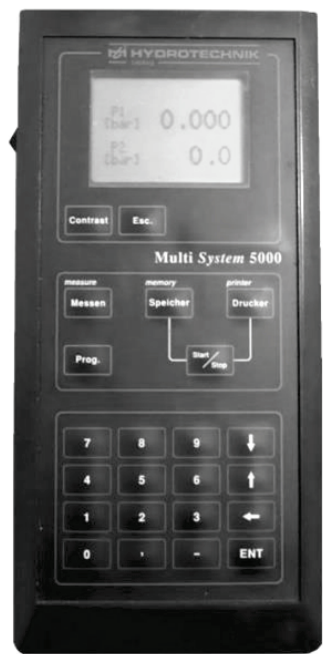

Figure 9 View of measuring equipment M5000 Hydrotechnik

\subsection{Determination of Eigenfrequency of LS System}

Dynamic properties of the LS system were investigated for the oil bulk modulus $K=7,34 \times 10^{8} \mathrm{~Pa}$, the pressure $p_{2}=8 \mathrm{MPa}$ and the moment of inertia on the rotary hydraulic motor $J_{M}=6 \times 10^{-2} \mathrm{~kg} \cdot \mathrm{m}^{-2}$. The bulk modulus value depends mainly on the working pressure $p_{2}$ and was experimentally obtained by volume method based on oil compressibility [17, 26, 27].

The eigenfrequency of the LS system for the abovementioned operating condition was investigated by three different methods.

\subsubsection{Experimental Measurement}

Experimental determination of dynamic properties of hydraulic systems can be realized by time-response characteristic (i.e. a unit step response), by response to a 
general input or by frequency characteristic (i.e. response to a periodic input signal at various excitation frequencies).

The experimental measurement of the system eigenfrequency $f_{0}$ was performed by a step change of the motor load and for the oil flow $Q_{2}=3,33 \times 10^{-5} \mathrm{~m}^{3} \cdot \mathrm{s}^{-1}$. For this reason the pressures $p_{1}$ and $p_{2}$ were suddenly increased (see Fig. 10). It is evident that the pressure drop across the proportional distributor remains constant (i.e. $\Delta p_{v}=p_{1}-p_{2}$ $\cong 1,4 \mathrm{MPa}$ ) independently of the motor load. Similarly, the flow $Q_{2}$ through the distributor PD and the motor HM is constant too.

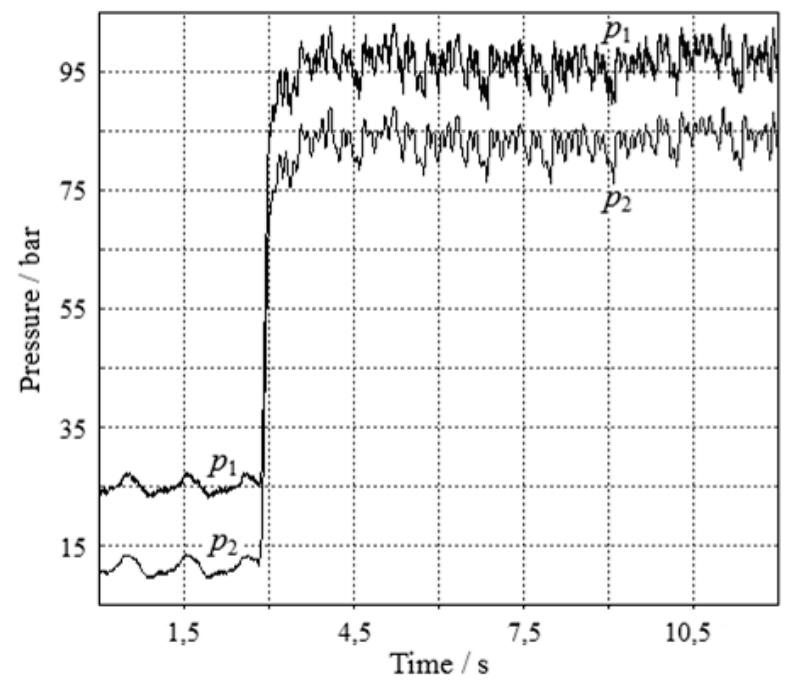

Figure 10 Time-response characteristics of pressures $p_{1}$ and $p_{2}$

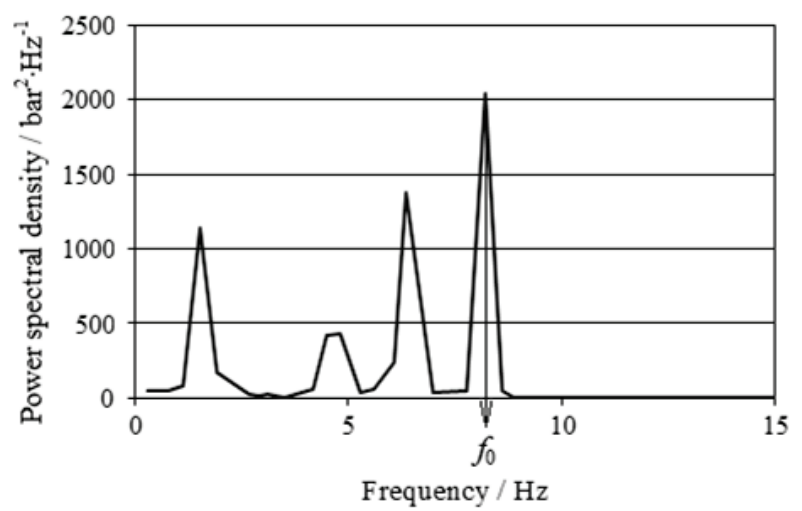

Figure 11 Frequency dependence of power spectral density

The eigenfrequency of the LS system under this operating condition was obtained by means of fast Fourier transform [28 $\div 33$, which is applied for spectral analysis. The result of the analysis is the power spectral density $G$ (i.e. a measure of energy at various excitation frequencies) [34]. The frequency dependence of the power spectral density is shown in Fig. 11 . The eigenfrequency $f_{0}$ of the investigated system is achieved at the maximum value of the power spectral density, in this case $f_{0}=8,20 \mathrm{~Hz}$ (see Fig. 11).

\subsubsection{Mathematical Simulation}

The mathematical simulation of dynamic behaviour of the investigated open center LS system was performed under these conditions:
1. The hydraulic pump is a source of constant flow $Q_{1}$ independently of motor loads.

2. The output pressure $p_{\mathrm{T}}$ (see Fig. 7) is supposed constant.

3. Resistances to motion and acceleration of the line between the distributor and the motor are much smaller in comparison with resistances to motion and acceleration of the rotary motor. For this reason, the resistances to motion and acceleration of the line are neglected.

Dynamic properties of the three-way pressure valve (see Fig. 12) and the proportional distributor for a load increase (i.e. motion of the slide valve of the pressure valve to the right) and a constant slide valve opening of the distributor are expressed by the equations [17]:

$$
\begin{aligned}
& m \cdot \frac{\mathrm{d}^{2} x}{\mathrm{~d} t^{2}}+b \cdot \frac{\mathrm{d} x}{\mathrm{~d} t}+k \cdot x=\left(p_{2}-p_{1}\right) \cdot A, \\
& 0=-S_{\mathrm{T}} \cdot x+Z_{\mathrm{T}} \cdot p_{1}+Z_{v} \cdot\left(p_{1}-p_{2}\right)-A \cdot \frac{\mathrm{d} x}{\mathrm{~d} t}, \\
& Q_{2}=Z_{v} \cdot\left(p_{1}-p_{2}\right)-A \cdot \frac{\mathrm{d} x}{\mathrm{~d} t},
\end{aligned}
$$

where: $m$ is reduced mass of the slide valve of the pressure valve $(m=0,21 \mathrm{~kg}), x$ is slide valve displacement of the pressure valve, $t$ is time, $b$ is damping coefficient of the slide valve of the pressure valve $\left(b=100 \mathrm{~N} \cdot \mathrm{s} \cdot \mathrm{m}^{-1}\right), k$ is spring stiffness of the pressure valve $\left(k=15329 \mathrm{~N} \cdot \mathrm{m}^{-1}\right)$, $A=\pi \cdot D^{2} / 4$ is slide valve area of the pressure valve $\left(A=2,54 \times 10^{-4} \mathrm{~m}^{2}\right), D$ is slide valve diameter $(D=18 \mathrm{~mm})$, $S_{\mathrm{T}}$ is pressure valve sensitivity $\left(S_{\mathrm{T}}=6,22 \mathrm{~m}^{2} \cdot \mathrm{s}^{-1}\right), Z_{v}$ is leakage permeability of the proportional distributor $\left(Z_{v}=1,2 \times 10^{-11} \mathrm{~N}^{-1} \cdot \mathrm{m}^{5} \cdot \mathrm{s}^{-1}\right)$, and $Z_{\mathrm{T}}$ is leakage permeability of the pressure valve $\left(Z_{\mathrm{T}}=6,4 \times 10^{-10} \mathrm{~N}^{-1} \cdot \mathrm{m}^{5} \cdot \mathrm{s}^{-1}\right)$.

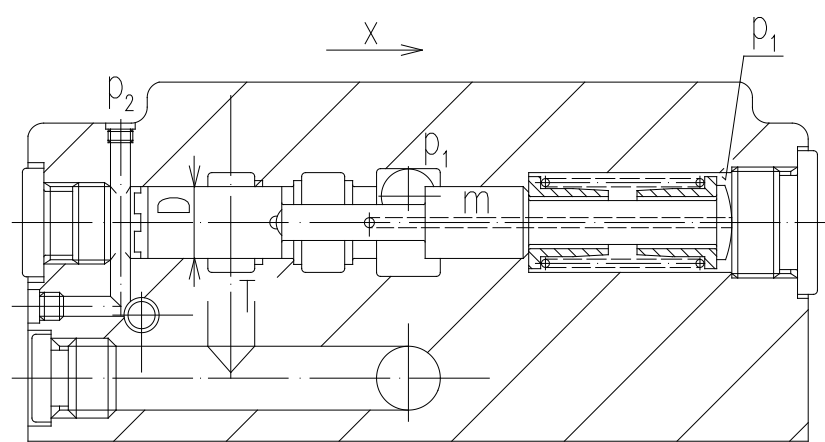

Figure 12 Cross section of pressure valve

Dynamic behaviour of the rotary hydraulic motor is described by the following equations [17]:

$\frac{\mathrm{d} Q_{M}}{\mathrm{~d} t}=\frac{p_{2}}{L_{\mathrm{M}}}-\frac{\Delta p_{\mathrm{ML}}}{L_{\mathrm{M}}}-\frac{R_{\mathrm{M}}}{L_{\mathrm{M}}} \cdot Q_{\mathrm{M}}$,
$\frac{\mathrm{d} p_{2}}{\mathrm{~d} t}=\frac{Q_{2}}{C_{\mathrm{M}}}-\frac{Q_{\mathrm{M}}}{C_{\mathrm{M}}}-\frac{Z_{\mathrm{M}}}{C_{\mathrm{M}}} \cdot p_{2}$,

where $Q_{\mathrm{M}}$ is real flow through the rotary motor, $\Delta p_{\mathrm{ML}}$ is motor load, $R_{\mathrm{M}}$ is motor resistance to motion $\left(R M=10^{10} \mathrm{~N}^{1} \cdot \mathrm{m}^{-5} \cdot \mathrm{s}\right), \quad L_{\mathrm{M}} \quad$ is motor resistance to acceleration $\left(L_{\mathrm{M}}=1,53 \times 10^{9} \mathrm{~N} \cdot \mathrm{m}^{-5} \cdot \mathrm{s}^{2}\right), \quad C_{\mathrm{M}}$ is motor capacity including oil volume in the supply line between 
the motor and the distributor $\left(C_{\mathrm{M}}=2,3 \times 10^{-13} \mathrm{~N}^{-1} \cdot \mathrm{m}^{5}\right)$, and $Z_{M}$ is leakage permeability of the rotary motor $\left(Z_{\mathrm{M}}=2,6 \times 10^{-13} \mathrm{~N}^{-1} \cdot \mathrm{m}^{5} \cdot \mathrm{s}^{-1}\right)$.

The values of the above-mentioned quantities were experimentally obtained and are described in detail in [17]. The above-mentioned system of the equations Eq. (9) $\div$ Eq. (13) was solved by the Runge-Kutta $4^{\text {th }}$ order method [35] using Mathcad software [36].

Fig. 13 shows the time dependence of the input pressure change $\Delta p_{1}$ for the step change of the motor load. The pressure $p_{2}$ was increased from $3 \mathrm{MPa}$ to $8 \mathrm{MPa}$ (i.e. $\Delta p_{\mathrm{ML}}=5 \mathrm{MPa}$ ) in this case. It is visible (see Fig. 13), that the pressure dependence is oscillating around the steady state value $\Delta p_{1} \cong 5 \mathrm{MPa}$ with the period of oscillation $T \cong 0,124 \mathrm{~s}$. The eigenfrequency $f_{0}$ of the investigated LS system in the given operating condition is subsequently determined from reciprocal of the period of oscillation:

$f_{0}=\frac{1}{T} \cong 8,04 \mathrm{~Hz}$

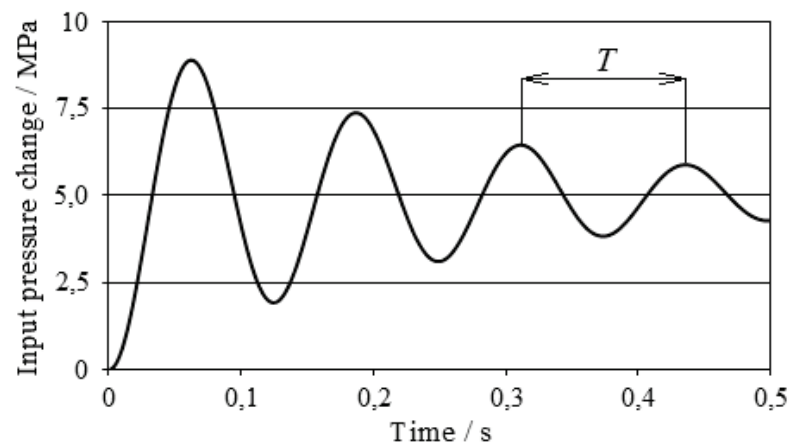

Figure 13 Time dependence of input pressure change $\Delta p_{1}$ due to step change of motor load

Fig. 14 demonstrates the time dependence of the output flow change $\Delta Q_{2}$ for the step change of the motor load $\Delta p_{\mathrm{ML}}=5 \mathrm{MPa}$. Similarly, the time dependence of the displacement change $\Delta x$ of the slide valve of the pressure valve for the same step change is shown in Fig. 15. It is evident that the time dependencies of the simulated quantities are again periodic (see Fig. 14 and Fig. 15) with the period of oscillation $T \cong 0,124 \mathrm{~s}$ and the eigenfrequency $f_{0}=8,04 \mathrm{~Hz}$ as in the case of the input pressure change (see Fig. 13).

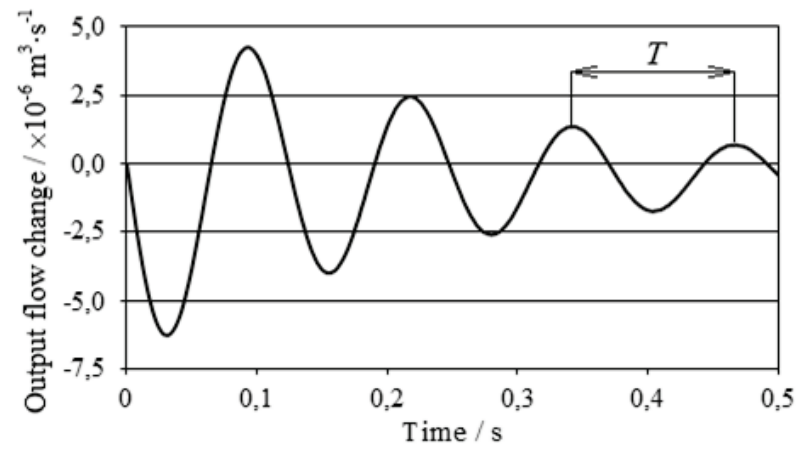

Figure 14 Time dependence of output flow change $\Delta Q_{2}$ due to step change of motor load

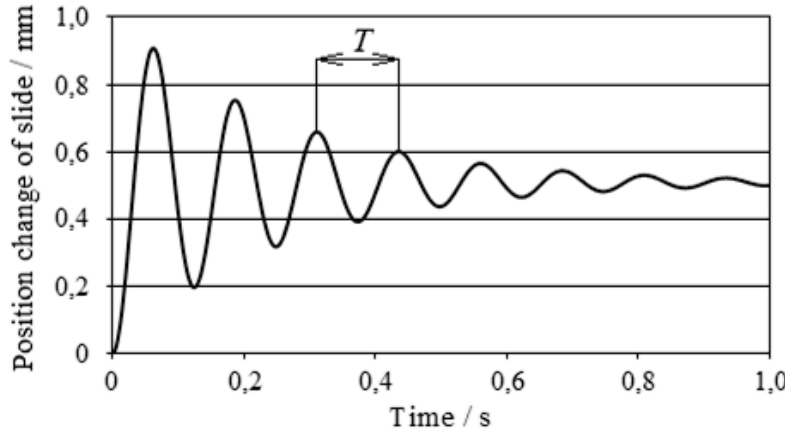

Figure 15 Time dependence of slide position change $\Delta x$ of pressure valve due to step change of motor load

It is possible to investigate the dynamics of the LS system on the basis of a step displacement change of the slide valve of the proportional distributor at a constant motor load too.

For example, a slide valve throttling (i.e. motion of the slide valve of the pressure valve to the left) of the proportional distributor is assumed. In this case, dynamic properties of the distributor and the three-way pressure valve are expressed by these equations [17]:

$$
\begin{aligned}
& m \cdot \frac{\mathrm{d}^{2} x}{\mathrm{~d} t^{2}}+b \cdot \frac{\mathrm{d} x}{\mathrm{~d} t}+k \cdot x=\left(p_{1}-p_{2}\right) \cdot A \\
& 0=S_{\mathrm{T}} \cdot x+Z_{\mathrm{T}} \cdot p_{1}+S_{v} \cdot \Delta y+Z_{v} \cdot\left(p_{1}-p_{2}\right)+A \cdot \frac{\mathrm{d} x}{\mathrm{~d} t}, \\
& Q_{2}=S_{v} \cdot y+Z_{v} \cdot\left(p_{1}-p_{2}\right)+A \cdot \frac{\mathrm{d} x}{\mathrm{~d} t}
\end{aligned}
$$

where $S_{v}$ is proportional distributor sensitivity $\left(S_{v}=1,11 \times 10^{-2} \mathrm{~m}^{2} \cdot \mathrm{s}^{-1}\right), \Delta y$ is slide valve throttling of the distributor, and $y$ is slide valve displacement of the distributor

Dynamic behaviour of the rotary hydraulic motor is described by Eq. (12) and Eq. (13) in this case.

The mathematical simulation was performed using Mathcad software for the step displacement change (i.e. for the step slide valve throttling) $\Delta y=-0,002 \mathrm{~m}$ of the slide valve of the proportional distributor and for a constant motor load.

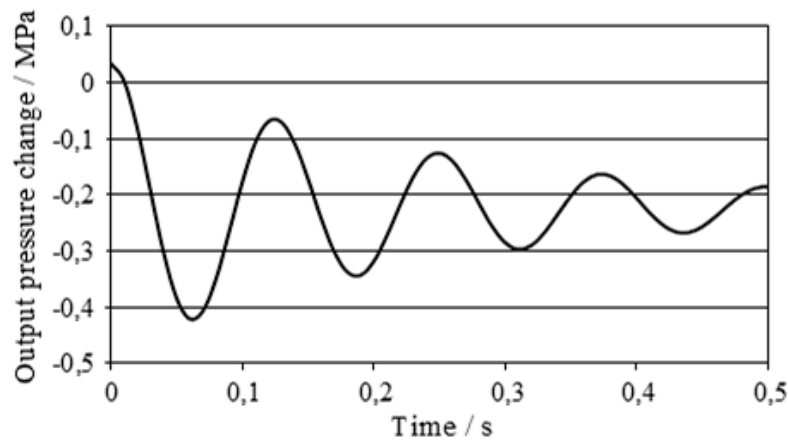

Figure 16 Time dependence of output pressure change $\Delta p_{2}$ due to step displacement change of slide valve of proportional distributor

Fig. 16 shows the time dependence of the output pressure change $\Delta p_{2}$ for the step displacement change of the slide valve of the distributor. It is evident that the pressure $p_{2}$ is slightly decreased in consequence of the slide valve throttling. The pressure course is damped periodic 
with the period of oscillation $T \cong 0,124 \mathrm{~s}$ and the eigenfrequency $f_{0}=8,04 \mathrm{~Hz}$, as in the case of the abovementioned step change of the motor load.

Similarly, the time dependencies of the output flow change $\Delta Q_{2}$ (see Fig. 17) and the displacement change $\Delta x$ of the pressure valve (see Fig. 18) are periodic with the same system eigenfrequency $f_{0}=8,04 \mathrm{~Hz}$ for the step displacement change of the slide valve of the proportional distributor.

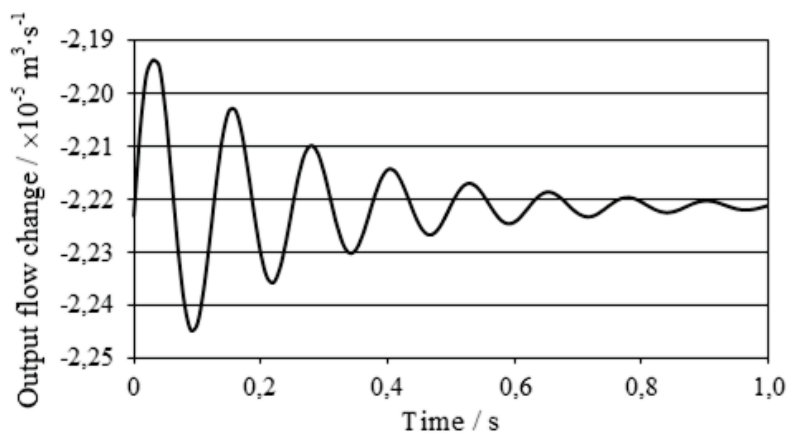

Figure 17 Time dependence of output flow change $\Delta Q_{2}$ due to step displacement change of slide valve of proportional distributor

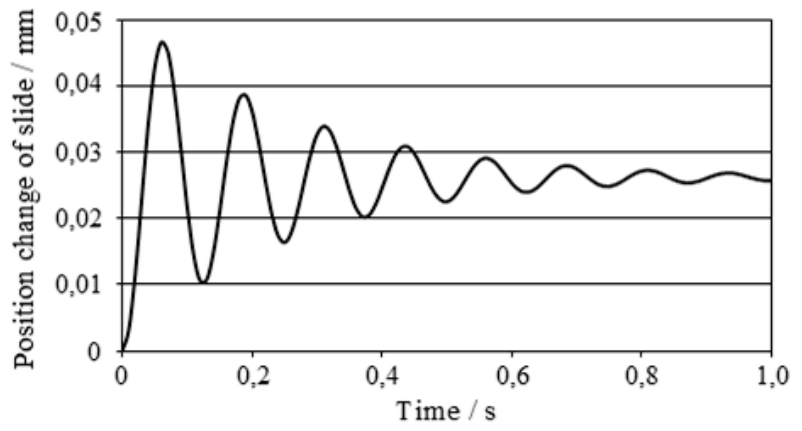

Figure 18 Time dependence of slide position change $\Delta x$ of pressure valve due to step displacement change of slide valve of proportional distributor

\subsubsection{Empirical Formula}

Empirical formulas are used for an approximate determination of eigenfrequency values under given operating conditions. There are different empirical formulas for determination of the eigenfrequency [12]. In case of the investigated LS system with the rotary hydraulic motor and minimum output pressure $p_{\mathrm{T}}$ (see Fig. 7 ), the system eigenfrequency is given by the equation [12, 17]:

$f_{0}=\frac{V_{\mathrm{M}}}{4 \cdot \pi^{2}} \cdot \sqrt{\frac{K}{J_{\mathrm{M}} \cdot\left(0,5 \cdot V_{\mathrm{M}}+V_{1}\right)}}$,

where $V_{\mathrm{M}}$ is geometric volume of the rotary motor $\left(V_{\mathrm{M}}=39,36 \times 10^{-6} \mathrm{~m}^{3}\right)$, and $V_{1}$ is oil volume between the motor and the proportional distributor $\left(V_{1}=149 \times 10^{-6} \mathrm{~m}^{3}\right)$.

Substituting the quantity values into Eq. (18), the system eigenfrequency $f_{0}=8,49 \mathrm{~Hz}$.

\subsection{Comparison of Methods}

The eigenfrequency values for the given operating condition of the investigated LS system were obtained by three different methods. Their comparison is adduced in Tab. 1.

Table 1 Values of eigenfrequencies determined by different methods

\begin{tabular}{|c|c|}
\hline Method & Eigenfrequency $f_{0} / \mathrm{Hz}$ \\
\hline Experimental measurement & 8,20 \\
\hline Mathematical simulation & 8,04 \\
\hline Empirical formula & 8,49 \\
\hline
\end{tabular}

It was found that the obtained values of the system eigenfrequency are very similar. It is visible mainly in comparison of the measured and simulated values. Empirical formulas are only used for an approximate determination of eigenfrequency values.

In case of systems with proportional valves [12], it is necessary to ensure the minimum system eigenfrequency $f_{0}$ $\min =4 \mathrm{~Hz}$. For this reason the investigated LS system is stable.

The eigenfrequency of hydraulic systems can be increased by different measures, e.g. by a perfect venting of working liquid, by elimination of liquid volume in hydraulic systems (i.e. by means of short hydraulic lines) and by location of a control valve near hydraulic motors.

\section{CONCLUSION}

Hydraulic systems are widely used in many areas, e.g. in manufacturing industry, aviation, agriculture and means of transport. Nevertheless, there are different requirements for these systems.

The aim of the paper was to investigate energy and dynamic properties of hydraulic systems. The first part of the paper was focused on comparison of different types of hydraulic systems in terms of their efficiency. The systems were compared from lower effective to energy saving. Advantages and disadvantages of these systems were also described. The second part of the paper was devoted to determination of the eigenfrequency of hydraulic systems. The eigenfrequency is a qualitative measure of drives. It is necessary to ensure a minimum value of the system eigenfrequency. The eigenfrequency was investigated for the open center Load-Sensing system, which belongs to energy saving hydraulic systems. The eigenfrequency was determined by means of three different methods, i.e. by experimental measurement, mathematical simulation and empirical formula. It can be concluded that a relatively large consensus was achieved between the experimental measurement and the mathematical simulation. Mathematical simulations are advantageous mainly from time and financial aspects. Furthermore, they are relatively simple and allow simulating different operating conditions of hydraulic systems. For these reasons, mathematical simulations are frequently applied at the present time. Empirical formulas are only used for an approximate determination of system eigenfrequencies under given operating conditions, e.g. in the design phase.

Energy and dynamic properties of hydraulic systems belong to important criteria during their operation. Energy consumption of hydraulic systems is connected with pressure and flow losses that have a negative influence on system efficiency and can lead to excessive heating and aging of working liquids. Therefore, the application of energy saving systems belongs to today's trends. Dynamic 
behaviour of hydraulic systems is connected with pressure and flow pulsations that have a negative effect on functionality and service life of hydraulic components, system tightness, stability, safety etc. In the worst case, these pulsations can lead to a system crash. High-amplitude pulsations occur at low excitation frequencies and eigenfrequencies of hydraulic systems. For this reason, it is necessary to avoid working processes of hydraulic systems at these frequencies in order to ensure their reliable operation.

\section{Acknowledgements}

The Ministry of Education, Youth and Sports was supported this work from the OP VVV project "Centre for Research of Advanced Mechatronic Systems" CZ.02.1.01/0.0/0.0/16_019/0000867.

\section{Symbols}

$A$ area $\left(\mathrm{m}^{2}\right)$

$b$ damping coefficient $\left(\mathrm{N} \cdot \mathrm{s} \cdot \mathrm{m}^{-1}\right)$

$C$ capacity $\left(\mathrm{N}^{-1} \cdot \mathrm{m}^{5}\right)$

$d$ displacement $(\mathrm{m})$

$D$ diameter $(\mathrm{m})$

$f_{0}$ eigenfrequency $(\mathrm{Hz})$

$G$ power spectral density $\left(\mathrm{bar}^{2} \cdot \mathrm{s}^{-1}\right)$

$i \quad$ electric current (A)

$J$ moment of inertia $\left(\mathrm{kg} \cdot \mathrm{m}^{-2}\right)$

$k \quad$ stiffness $\left(\mathrm{N} \cdot \mathrm{m}^{-1}\right)$

$K$ bulk modulus $(\mathrm{Pa})$

$L \quad$ resistance to acceleration $\left(\mathrm{N} \cdot \mathrm{m}^{-5} \cdot \mathrm{s}^{2}\right)$

$m$ mass $(\mathrm{kg})$

$p$ pressure $(\mathrm{Pa})$

$\Delta p$ pressure change, pressure drop $(\mathrm{Pa})$

$P$ power $(\mathrm{W})$

$Q$ flow $\left(\mathrm{m}^{3} \cdot \mathrm{s}^{-1}\right)$

$\Delta Q$ flow change $\left(\mathrm{m}^{3} \cdot \mathrm{s}^{-1}\right)$

$R$ resistance to motion $\left(\mathrm{N}^{1} \cdot \mathrm{m}^{-5} \cdot \mathrm{s}\right)$

$S \quad$ valve sensitivity $\left(\mathrm{m}^{2} \cdot \mathrm{s}^{-1}\right)$

$t$ time (s)

$T$ period of oscillation (s)

$u$ voltage $(\mathrm{V})$

$V$ volume $\left(\mathrm{m}^{3}\right)$

$V_{\mathrm{M}}$ geometric volume of hydraulic motor $\left(\mathrm{m}^{3}\right)$

$x \quad$ slide valve displacement of pressure valve (m)

$\Delta x$ displacement change $(\mathrm{m})$

$y \quad$ slide valve displacement of distributor (m)

$\Delta y$ displacement change $(\mathrm{m})$

$Z \quad$ leakage permeability $\left(\mathrm{N}^{-1} \cdot \mathrm{m}^{5} \cdot \mathrm{s}^{-1}\right)$

$\alpha$ angular displacement $\left(^{\circ}\right)$

$\eta$ efficiency

$\mu$ flow coefficient

$\pi$ Ludolph's number

$\rho$ density $\left(\mathrm{kg} \cdot \mathrm{m}^{-3}\right)$

\section{Abbreviations}

$\begin{array}{ll}\text { B } & \text { brake } \\ \text { C } & \text { cooler } \\ \text { CB } & \text { control block } \\ \text { CV } & \text { control valve }\end{array}$

F filter

FM flowmeter

FR flow regulator

HM hydraulic motor

HP hydraulic pump

LS load-sensing

LV logical valve

M manometer

M hydraulic motor

ML motor load

PD proportional distributor

PR pressure regulator

PS pressure sensor

PV pressure valve

$\mathrm{R}$ pressure reducing valve

RV relief valve

T tank

TM thermometer

TV throttle valve

UV unidirectional valve

$\mathrm{V} \quad$ valve

\section{REFERENCES}

[1] Alleyne, A. \& Liu, R. (2000). A simplified approach to force control for electro-hydraulic systems. Control Engineering Practice, 8(12), 1347-1356. https://doi.org/10.1016/S0967-0661(00)00081-2

[2] Bach, D., Schmich, F., Masselter, T., \& Speck, T. (2015). A review of selected pumping systems in nature and engineering-potential biomimetic concepts for improving displacement pumps and pulsation damping. Bioinspiration \& Biomimetics, 10, p. 051001 . https://doi.org/10.1088/1748-3190/10/5/051001

[3] Mitrev, R., Janosevic, D., \& Marinkovic, D. (2017). Dynamical modelling of hydraulic excavator considered as a multibody system. Tehnički vjesnik, 24(Supplement 2), 327338. https://doi.org/10.17559/TV-20151215150306

[4] Ge, L., Quan, L., Zhang, X., Zhao, B., \& Yang, J. (2017). Efficiency improvement and evaluation of electric hydraulic excavator with speed and displacement variable pump. Energy Conversion and Management, 150, 62-71. https://doi.org/10.1016/j.enconman.2017.08.010

[5] Lovrec, D., Tic, V., \& Tasner, T. (2017). Dynamic behaviour of different hydraulic drive concepts - comparison and limits. International journal of simulation modelling, 16(3), 448-457. https://doi.org/10.2507/IJSIMM16(3)7.389

[6] Immonen, P., Ponomarev, P., Aman, R., Uusi-Heikkila, J., Laurila, L., Handroos, H., Niemela, M., Pyrhonen, J., \& Huhtala, K. (2016). Energy saving in working hydraulics of long booms in heavy working vehicles. Automation in construction, 65, 125-132. https://doi.org/10.1016/j.autcon.2015.12.015

[7] Li, L., Huang, H., Zhao, F., Triebe, M. J., \& Liu, Z. (2017). Analysis of a novel energy-efficient system with doubleactuator for hydraulic press. Mechatronics, 47, 77-87. https://doi.org/10.1016/j.mechatronics.2017.08.012

[8] Lisowski, E. \& Rajda, J. (2013). CFD analysis of pressure loss during flow by hydraulic directional control valve constructed from logic valves. Energy Conversion and Management, 65, 285-291. https://doi.org/10.1016/j.enconman.2012.08.015

[9] Henderson, R. (2006). Design, simulation, and testing of a novel hydraulic power take-off system for the Pelamis wave energy converter. Renewable energy, 31(2), 271-283. https://doi.org/10.1016/j.renene.2005.08.021 
[10] Koegler, A. F., Haselmann, D., Alt, N. S. A., \& Schluecker, E. (2017). Experimental Characterization of a Flow-through Pulsation Damper Regarding Pressure Pulsations and Vibrations. Chemical Engineering \& Technology, 40(1), 162-169. https://doi.org/10.1002/ceat.201600175

[11] Czerwinski, A. \& Luczko, J. (2015). Parametric vibrations of flexible hoses excited by a pulsating fluid flow, Part II: Experimental research. Journal of fluids and structures, 55, 174-190. https://doi.org/10.1016/j.jfluidstructs.2015.03.007

[12] Dörr, H., Ewald, R., Hutter, J., Kretz, D., Liedhegener, F., \& Schmitt, A. (1986). The Hydraulic Trainer Volume 2 Proportional and Servo Valve Technology. Mannesmann Rexroth GmbH, Lohr am Main.

[13] Šuránek, P., Mahdal, M., \& Tůma, J. (2014). Modelling and simulation of an active damped structure. Proceedings of the $201415^{\text {th }}$ International Carpathian Control Conference / Velké Karlovice, 588-591. http://ieeexplore.ieee.org/document/6843673/

[14] Weishaupt, E. \& Völker, B. (1995). Energiesparende elektrohydraulische Schaltungskonzepte. Ölhydraulik und Pneumatik, 39(2), 106-112.

[15] Enver, U. (2016). Efficiency analysis of induction air heater and investigation of distribution of energy losses. Tehnički vjesnik, 23(5), 1259-1267. https://doi.org/10.17559/TV-20151122224719

[16] Püschel, R. (1995). Leistungssteigerung durch RexrothKomponenten und -systeme am Beispiel Spritzgießmaschinen. Rexroth Information Quartelly, 4, 2327.

[17] Vašina, M. (2000). Energy saving hydraulic systems of lifting and loading equipment mounted on lorries. VŠB Technical University in Ostrava, Czech Republic.

[18] Exner, H., Freitag, R., Geis, H., Lang, R., Oppolzer, J., Schwab, P., Sumpf, E., Ostendorff, U., \& Reik, M. (1991). The Hydraulic Trainer Volume 1 - Basic Principles and Components of Fluid Technology. Mannesmann Rexroth $\mathrm{GmbH}$, Lohr am Main.

[19] Deticek, E., Gubeljak, N., \& Kastrevc, M. (2017). Design of Lyapunov based nonlinear velocity control of electrohydraulic velocity servo systems. Tehnički vjesnik, 24(3), 745-751. https://doi.org/10.17559/TV-20160930073953

[20] Hu, Q. Y., Zhang, H., Tian, S. J., \& Qin X. X. (2017). Model Reduction of a Load-Sensing Hydraulic System via Activity Index Analysis. Strojniski vestnik, 63(1), 65-77. https://doi.org/10.5545/sv-jme.2016.3450

[21] Paszota, Z. (2007). Energy Saving in a Hydraulic Servomechanism System - Theory and Examples of Laboratory Verification. Brodogradnja, 58(2), 146-157.

[22] Siminiati, D. \& Dubrovič, Ž. (2008). Contribution to Defining Hydrostatic Steering Parameters. Engineering Review, 28(1), 99-108.

[23] Lovrec, D., Kastrevc, M., \& Ulaga, S. (2009). Electrohydraulic load sensing with a speed-controlled hydraulic supply system on forming-machines. The International Journal of Advanced Manufacturing Technology, 41(11-12), 1066-1075. https://doi.org/10.1007/s00170-008-1553-y

[24] Chiang, M. H. \& Chien, Y. W. (2003). Parallel Control of Velocity Control and Energy-Saving Control for a Hydraulic Valve-Controlled Cylinder System Using Self-Organizing Fuzzy Sliding Mode Control. JSME International Journal Series C: Mechanical Systems Machine Elements and Manufacturing, 46(1), 224-231. https://doi.org/10.1299/jsmec.46.224

[25] Kemmetmüller, W., Fuchshumer, F., \& Kugi, A. (2010). Nonlinear pressure control of self-supplied variable displacement axial piston pumps. Control Engineering Practice, 18(1), 84-93. https://doi.org/10.1016/j.conengprac.2009.09.006

[26] Hružík, L., Vašina, M., \& Bureček, A. (2012). Evaluation of Bulk Modulus of Oil System with Hydraulic Line.
Proceedings of the International Conference Experimental Fluid Mechanics 2012 / Hradec Králové, 01041. https://doi.org/10.1051/epjconf/20134501041

[27] Vašina, M. \& Hružík, L. (2008). Measurement of Modulus of Elasticity of Liquids. Fine Mechanics and Optics, 53(5), 146-147. http://jmo.fzu.cz/2008/Jmo-05/JMO-200805.pdf

[28] Paar, V., Pavin, N., Basar, I., Rosandić, M., Luketin, I., \& Žinić S. D. (2004). Spectral Densities and Frequencies in the Power Spectrum of Higher Order Repeat Alpha Satellite in Human DNA Molecule. Croatica Chemica Acta, 77(1-2), 73-81.

[29] Kušnerová, M., Foldyna, J., Sitek, L., Valíček, J., Hloch, S., Harničárová, M., \& Kadnár, M. (2012). Innovative Approach to Advanced Modulated Waterjet Technology. Tehnički vjesnik, 19(3), 475-480.

[30] Cooley, J. W., Lewis, P. A. W., \& Welch, P. D. (1969). The Fast Fourier Transform and Its Applications. IEEE Transactions on Educations, 12(1), 27-34. https://doi.org/10.1109/TE.1969.4320436

[31] Kopáčik, A., Lipták, I., Kyrinovič, P., \& Erdélyi, J. (2013). Dynamic Deformation Monitoring of a Technological Structure. Geodetski list, 67(3), 161-174.

[32] Šostarić, D., Žagar, D., \& Samardžić, I. (2012). Influence of Electromagnetic Field on Environment in TIG welding process. Strojarstvo, 54(1), 59-69.

[33] Song, S., Ma, H., \& Zhang, Z. (2017). Spectral correction method based on improved flat-top convoluted window for parameter estimation of power harmonic. Tehnički vjesnik, 24(1), 79-87. https://doi.org/10.17559/TV-20160525173140

[34] Marzbandrad, J. \& Hoseinpour, A. (2017). Structural optimization of MacPherson control arm under fatigue loading. Tehnički vjesnik, 24(3), 917-924. https://doi.org/10.17559/TV-20150225090554

[35] Ralston, A. (1962). Runge-Kutta Methods with Minimum Error Bounds. Mathematics of Computation, 16(80), 431437. https://doi.org/10.1090/S0025-5718-1962-0150954-0

[36] Dudek, P. (1992). Mathcad - User's Guide. Grada, Prague.

\section{Contact information}

Martin VAŠINA, Associate Professor

(Corresponding author)

VŠB - Technical University of Ostrava

Faculty of Mechanical Engineering

17. listopadu 15/2172, 70833 Ostrava-Poruba, Czech Republic

E-mail: martin.vasina@vsb.cz

Lumír HRUŽíK, Associate Professor

VŠB - Technical University of Ostrava

Faculty of Mechanical Engineering

17. listopadu 15/2172, 70833 Ostrava-Poruba, Czech Republic

E-mail: lumir.hruzik@vsb.cz

Adam BUREČEK, Research Assistant

VŠB - Technical University of Ostrava

Faculty of Mechanical Engineering

17. listopadu 15/2172, 70833 Ostrava-Poruba, Czech Republic

E-mail: adam.burecek@vsb.cz 